\title{
The role of detail spatial data resulted from unmanned aerial vehicle for tourism area planning in Karst Area, Gunungkidul
}

Warsini Handayani, Yudhistira Tri Nurteisa, Mohammad Isnaini Sadali

Warsini Handayani, Yudhistira Tri Nurteisa, Mohammad Isnaini Sadali, "The role of detail spatial data resulted from unmanned aerial vehicle for tourism area planning in Karst Area, Gunungkidul," Proc. SPIE 11311, Sixth Geoinformation Science Symposium, 113110N (21 November 2019); doi: 10.1117/12.2548391

Event: Sixth Geoinformation Science Symposium, 2019, Yogyakarta, Indonesia 


\title{
The Role of Detail Spatial Data Resulted from Unmanned Aerial Vehicle for Tourism Area Planning in Karst Area, Gunungkidul
}

\author{
Warsini Handayani*a, Yudhistira Tri Nurteisa ${ }^{\mathrm{b}}$, Mohammad Isnaini Sadalic \\ a Department of Geo-Technology, Vocational College, Universitas Gadjah Mada, Bulaksumur,

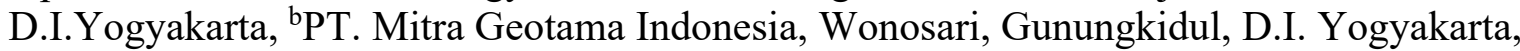 \\ ${ }^{c}$ Department of Regional Development, Faculty of Geography, Universitas Gadjah Mada, \\ Bulaksumur, D.I. Yogyakarta, Indonesia
}

\begin{abstract}
Karst area has a fascinating tourist attraction, especially special interest tourism such as cave tubing in Kalisuci tourism area, Gunungkidul, Yogyakarta. The presence of visitor restrictions has an impact on tourism waiting times. However, it also spurs the development potential besides cave exploration. Planning and development of tourist sites that include locations and consider the existing conditions of the region can only be done optimally with data and spatial analysis. On the other hand, the specific terrain condition, steeply hilly karst, is a great challenge in planning and developing karst area. This research aims to build primary spatial data in the Kalisuci Tourism area and provide a reference about the role of spatial data produced for planning special interest tourism in Kalisuci karst area, Gunungkidul. Primary spatial data was built from data acquisition using Unmanned Aerial Vehicle (UAV) technology. This data is fundamental in the planning inputs for the development of the Kalisuci special interest tourism area in supporting the planning of tourist areas in accordance with terrain conditions. In addition, the data obtained from acquisition with UAVs are expected to provide detail spatial data collection, which is currently very limited. The resulting data are small format aerial photography, aerial photo imagery (orthorectification results), and digital elevation models in the form of Digital Surface Model (DSM). This paper discusses how far the data generated can contribute to overall field observation and assist in planning special interest tourism in a karst area.
\end{abstract}

Keywords: detail spatial data, UAV, DSM, karst, tourism area planning

\section{INTRODUCTION}

\subsection{Background}

Unmanned Aerial Vehicle (UAV) is one of the technologies that is increasingly popular recently for spatial data acquisition. The advantage of this data acquisition is that it can be done at any time, higher speed, the high novelty of information, low cost in term of high quality spatial data products, as well as providing wide application prospects [Rosaji, 2013, Yu et al., 2018]. Data acquisition using UAV that combined with ground control points measurement resulted two main products, orthophoto and topographic models or digital surface models (DSM). Orthophoto can reach more than $0.25 \mathrm{~m}$ spatial resolution while DSM vertical accuracy between 0.2 - 3.2 meters [7, 8, 9, 13]. UAV can provide better resolution data in both temporal and spatial aspects [14]. Based on Geospatial Information Agency's Regulation number 15 year 2014 concerning the Basic Map Accuracy Technical Guidelines [6], this accuracy specifications can be used for large-scale mapping between 1: 10,000 to 1:2,500. Yeh et al [15] used UAV to generate DSM and compared it with conventional surveying technique. They resulted high accuracy DSM product with $1,58 \mathrm{~cm}$ in resolution and found it more efficient for topographic mapping. It is clear that UAV can provide accurate topography data product and substitute conventional surveying methods in considerably efficient manner.

UAVs are increasingly being used for various thematic mapping; for agriculture and plantations, vegetation studies, disaster mapping, urban studies, and tourism area planning. In agricultural application and vegetation study by Food and Agriculture Organization (FAO) [5], UAV provide high resolution elevation maps for tree count and height as well as area and volume estimation. In agricultural thematic analysis, UAV also compatible for soil analysis and health assessment [2]. In flood risk study [4], Digital Elevation Model (DEM) was used for flood assessment and resulted less 
than $30 \mathrm{~cm}$ difference compared with Lidar data model. UAV also have advantages for urban planning, data collection and transport task utility tools [3] as well as primary data for urban phenomena extraction.

In general, UAV products that are widely used are orthophoto for semantic information extraction because processing is quite practical. DSM as the primary product of data acquisition with UAVs must be processed into DTM for topographic analysis. Unlike the DTM that represents the height of the earth's surface, DSM represents true surface including objects on the surface of the earth (e.g. buildings, trees, woodland) [1]. Some of the obstacles in this extraction are in hilly areas and meeting vegetation because the limited reference to ground elevation as a processing reference for DSM becomes DTM. Examples of this field are found in hilly areas such as in the Gunungkidul karst area. Utilization of data from the acquisition of UAV is a challenge in this area. On the other hand, the specific terrain condition, steeply hilly karst, is a great challenge in planning and developing karst area.

For tourism planning, orthophoto and DSM area very important for supporting planning in accordance with terrain conditions. In addition, the data obtained from acquisition with UAVs are expected to provide detailed spatial data collection, which is currently severely limited. This research aims to build primary spatial data in the Kalisuci Tourism area and provide a reference about the role of spatial data produced for planning special interest tourism in Kalisuci karst area, Gunungkidul.

\subsection{Study Area}

The research area is in Pacarejo Village, Semanu, Gunungkidul, Special Province of Yogyakarta. Geologically, this area has karst topography, a topography formed from the dissolution of soluble rocks such as limestone, with rivers passing through underground caves. The river located at extermely lower elevation than surrounding, appear as cliffs on the river side.
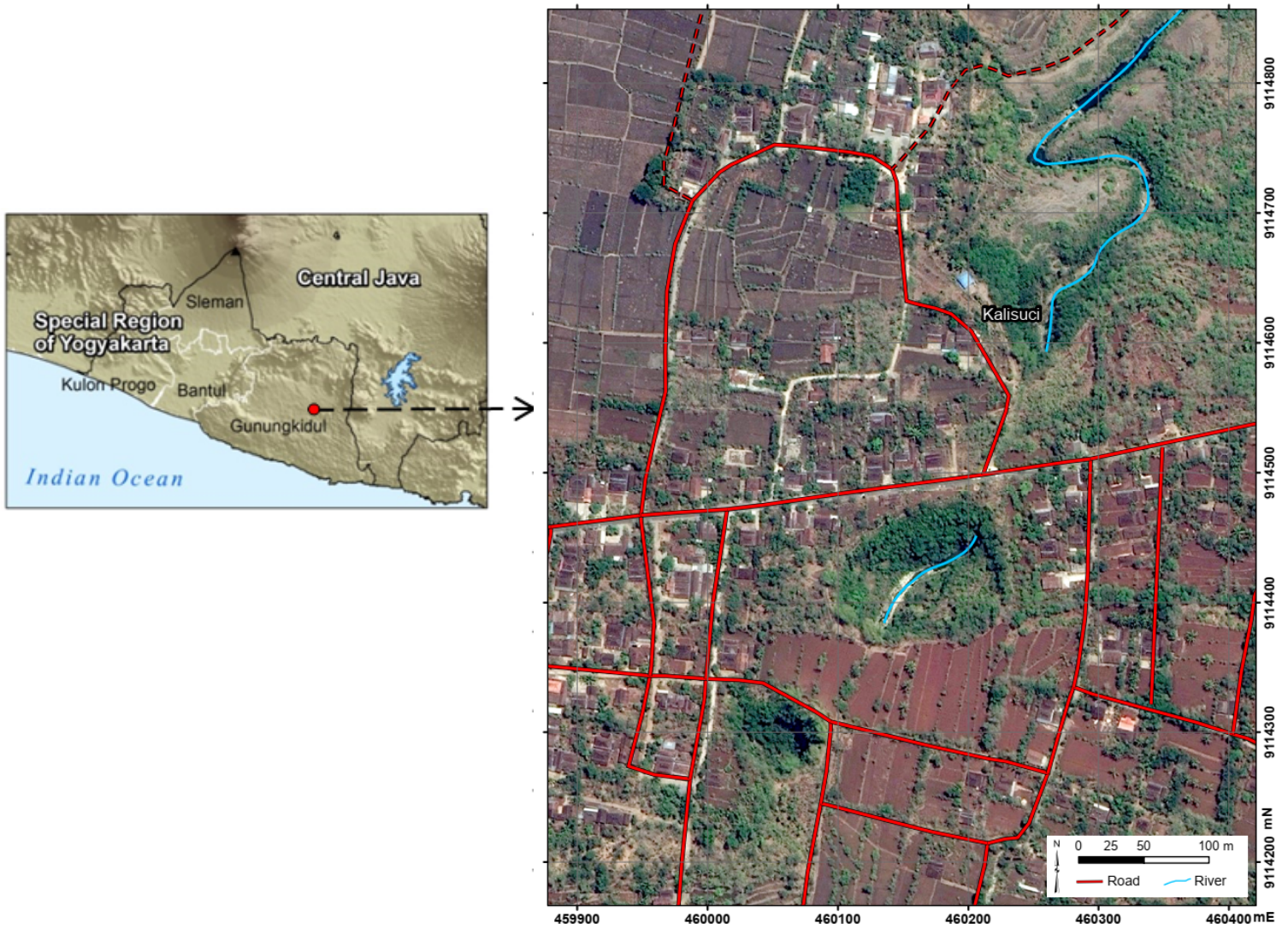

Figure 1. Location of Kalisuci tourism area in Gunungkidul, D.I.Yogyakarta (Data Source: Google Earth) 
As one of the geosites in Geopark Gunung Sewu which since 2015 was designated as the Global Geopark Network (GGN) by UNESCO, the Kalisuci tourist area offers major tourist attractions at underground cave namely cave tubing, a combination of caving and bodyrafting. The presence of visitor restrictions has an impact on tourism waiting times. Each time, it was limited only 20-25 person to enter the cave each half hour and total 150 visitors in a day. It was setted by Kalisuci community to maintain visitor's comfort and safety standart as well as cave sustainability. This tourism also confined by season particularly at rainy day; cave tubing activity will be closed. In addition to the needs of tourism development, natural conditions also pose challenges in tourism planning in this area.

\section{METHODOLOGY}

\subsection{Data and Instrument}

Firstly, aerial data acquisition used UAV instruments in-flight mission, while Geodetic GNSS was used in control points measurement. Fix Wing UAV was used as platform and pocket camera as the sensor. Agisoft software was used in data processing to generate orthophoto and DSM from aerial photos and control points data. These primary data (orthophoto and DSM) expected to represent detail object and high accuracy in centimetre so that it can represent terrain condition close to reality. In addition, ArcGIS software was used in spatial modeling and analysis of orthophoto and DSM.

\subsection{Method}

This research begins with the preparation and information excavation to obtain more detailed information about the tourism area condition as well as determine the boundary of the study area from the results of discussions (FGD) and alternative types of attractions to be developed. The boundary of the study area was used as a reference in aerial data acquisition planning.

In general, the use of UAV for spatial data acquisition includes three main stages: pre-flight, in-flight and post-flight [10, 11]. At pre-flight stages, some preparation of aerial data acquisition was made such as equipment (UAV, premark, Geodetic Global Navigation Satellite Systems (GNSS)), flight plan, flight mission schedule, map distribution of Ground Control Points (GCP) and Independent Check Points (ICP), and team. In-flight stages is a term of aerial data acquisition or aerial mission process which consist of GCP-ICP premarks fixing, aerial photography using UAV, and GCP-ICP measurement using Geodetic GNSS. The GCP-ICP measurement used RTK (Real Time Kinematic) method and connected to INA-CORS BIG (Indonesian- Continuously Operating Reference Station) to increase position accuracy [12]. This stage resulted aerial photos and GCP-ICP measurement data that integrally processed in post-flight stage using digital photogrammetry software. Finally, it generated primary spatial data, orthophoto and digital surface model (DSM).
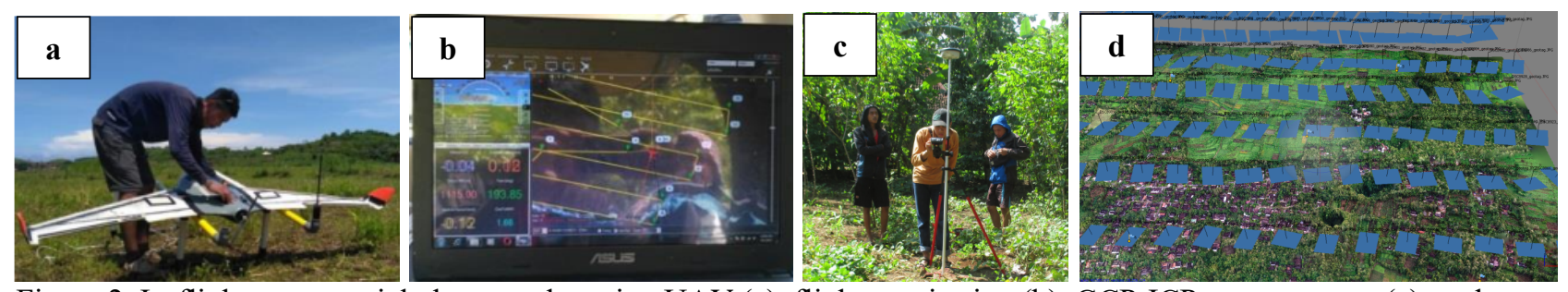

Figure 2. In-flight stage: aerial photography using UAV (a), flight monitoring (b), GCP-ICP measurement (c), and postflght: data processing using digital photogrammety software (d).

After the primary high-resolution spatial data (orthophoto and DSM) obtained, the research continued by locating and modeling each attraction. The attraction planning location derived from field observation and discussion with Kalisuci Community were plotted into the map (orthophoto). Landuse interpretation was used as an analysis of orthophoto data and DSM to observe if the location was suitable for the attractions plan. Modeling and analysis involved viewshed analysis and topographic analysis such as for observing view range of viewing post and analysing suitable slope for the attraction. diagram of research methodology can be seen in Figure 3. 


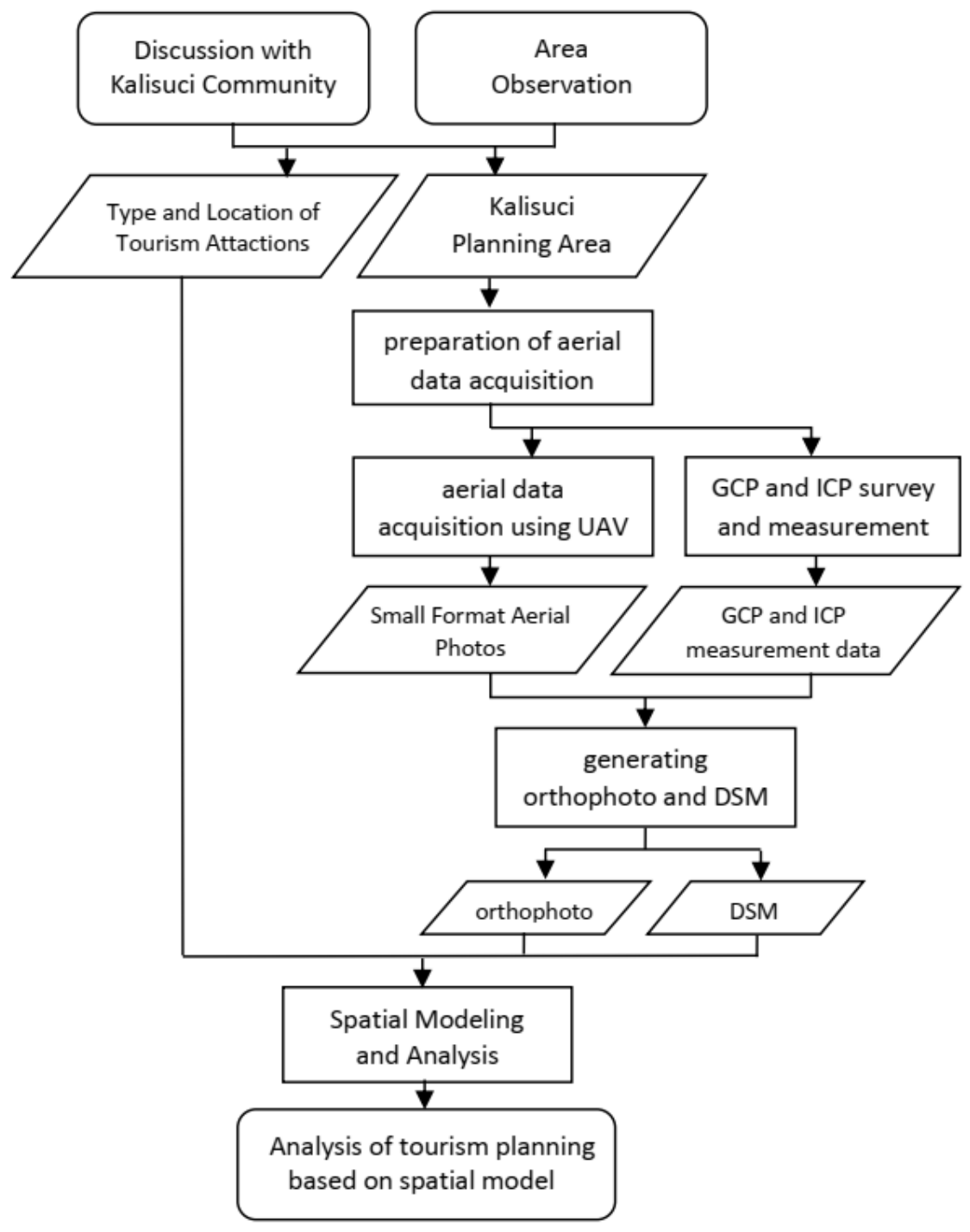

Figure 3. Diagram of Research Methodology

\section{RESULT}

\subsection{Terrain Condition}

The aerial data acquisition resulted in aerial photos sequence with ground square distance (GSD) $\pm 7 \mathrm{~cm}$. The orthophoto and DSM have vertical accuracy of $0,7 \mathrm{~m}$ and horizontal accuracy $15 \mathrm{~cm}$. Both data were very detailed data input for large- ground scale mapping. Based on the orthophoto, Kalisuci tourism area are mostly covered by buildings and vegetation, as well as woodland and agricultural areas around it (Figure 4). 

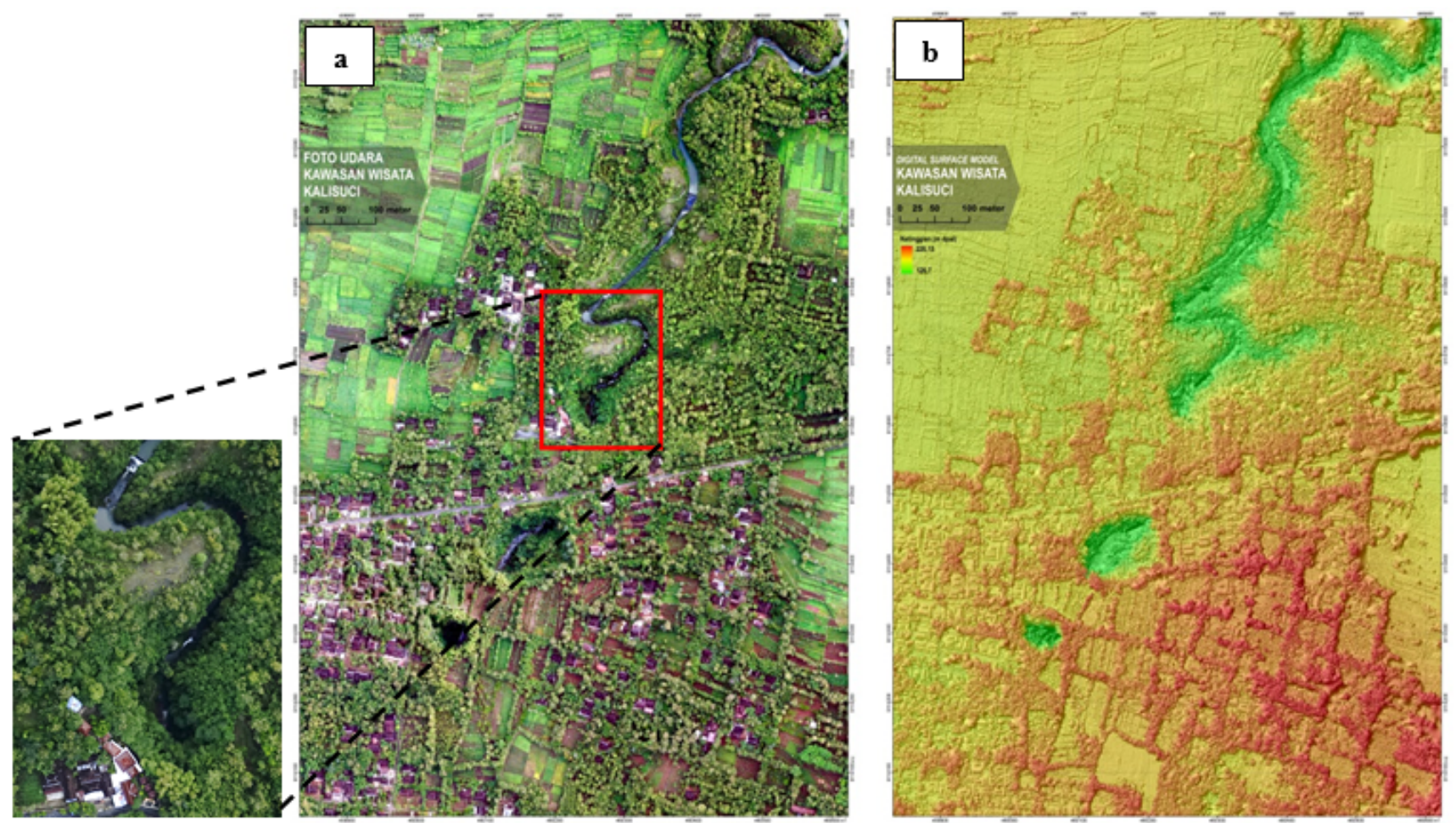

Figure 4. (a) Orthophoto of Kalisuci tourism area and (b) Digital Surface Model resulted from post-processing UAV photos

Kalisuci area has steep river cane with approximately 30-40 meters height from the riverbank, hilly topography covered by vegetation. In some areas, there is a reasonably flat area, potential to be used for the attraction development plan, particularly viewing point (tower) and flying fox (Figure 5).
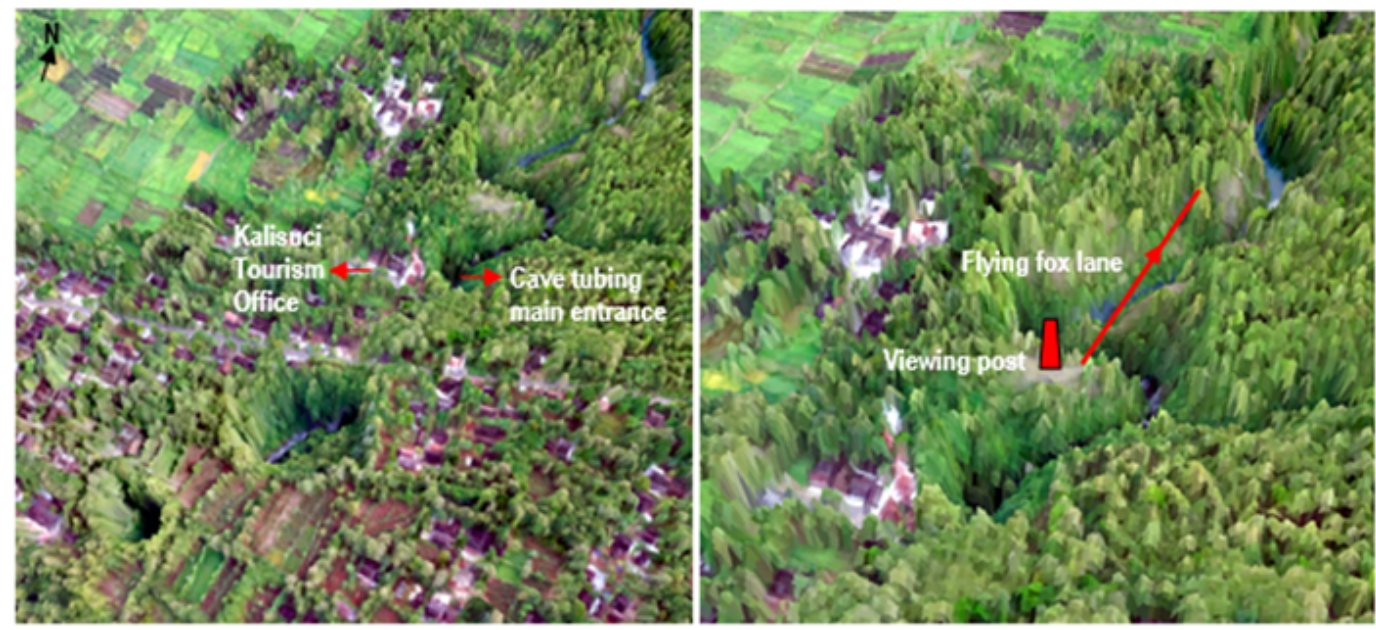

Figure 5. 3D Imagery of Kalisuci and sample of attaction plan situated close to edge of river cliff

\subsection{Tourism Planning Assessment}

Tourist attractions that are planned to be developed are the viewing post, jogging track, a bridge connecting the west and east sides of the river, flying fox, and restaurant on the east side. In this Previous field observation carried out at the 
planning location was guided by Kalisuci tour manager. The location of the attractions is planned in a relatively wide and flat area.

Viewing post is an attraction, also functioning as the monitor tower, is expected to reduce visitors crowd in the secretariat lounge area. The location of the tower of view is attempted to fulfil some parameter such as: build in a relatively higher area with excellent visibility, not too far from the secretariat (to facilitate the information delivery), and located in a wide area where it can be developed as waiting area with several chairs and gazebos for visitors. Based on the planning, a visibility analysis was created using DSM. This method was applied in the analysis because of the advantages in producing a visible and nonvisible area from observations.
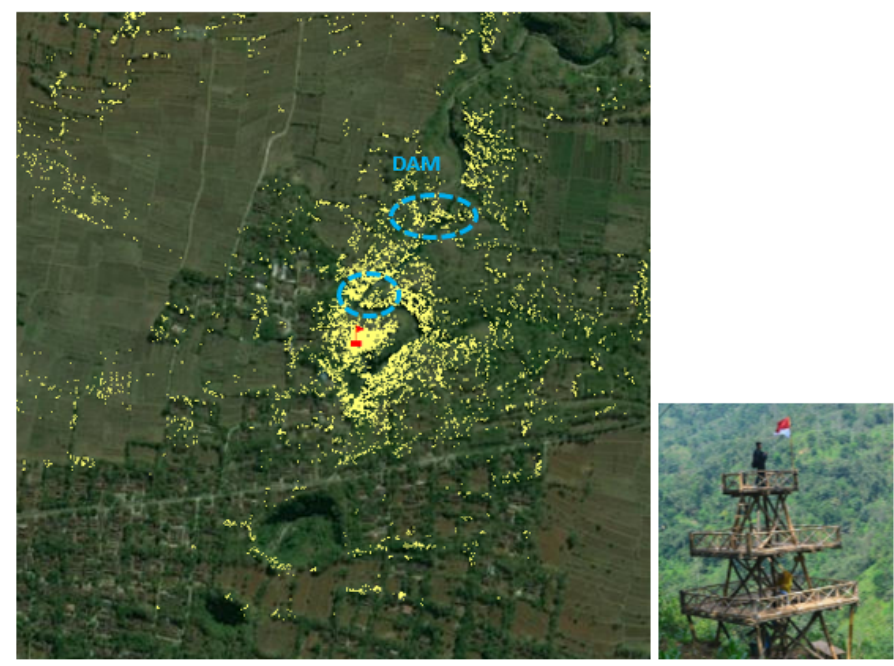

Figure 6. Viewshed model of visible (yellow area) and nonvisible area, based on 7 meters height viewing post

Flying Fox is planned to be a tourist attraction before visitor entering the outbound arena. Site selection of flying fox lane utilizes orthophoto and DSM data to find open locations, avoid obstacles, have the appropriate slope (according to the sliding speed) and the length of the crossing measured for equipment needs. Based on spatial modeling, the location of the flying fox starting point was set near the viewing post to the north across the river meander with a rope length of $168 \mathrm{~m}$ and a slope of 7\% (Figure 5). Selected locations have several advantages over long trajectories, suitable slope, passing 2 river bodies and a ridge, and can be a link between the east and west area of Kalisuci for further development.

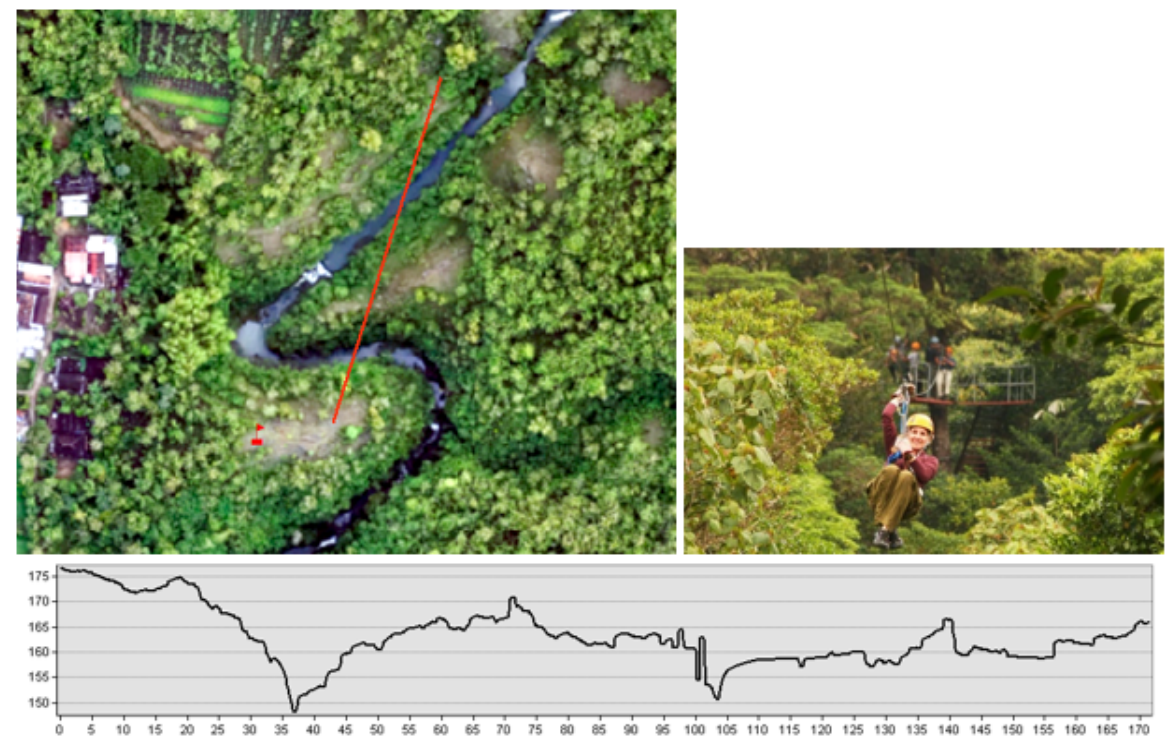

Figure 7. Flying fox planning location and the terrain depiction that goes through with 10 meters height difference (start from 176 to 166 meter above mean sea level at finishing point) and a crossing $168 \mathrm{~m}$ length of at $7 \%$ slope. 
A bridge will be located near flying fox lane is used to open up access to the area to the east of the river. This could be the beginning of the utilization of the area around the river, which was previously considered very limited. With the opening of the east side of the river area, other activities can be built, such as outbound area, restaurants, and rest area. Bridge can be developed at flat area with a similar height, and at the end of the bridge must be a relatively gentle slope to make a pathway. The location is chosen using DSM data where, with this method a location of the same height can be easily interpreted.
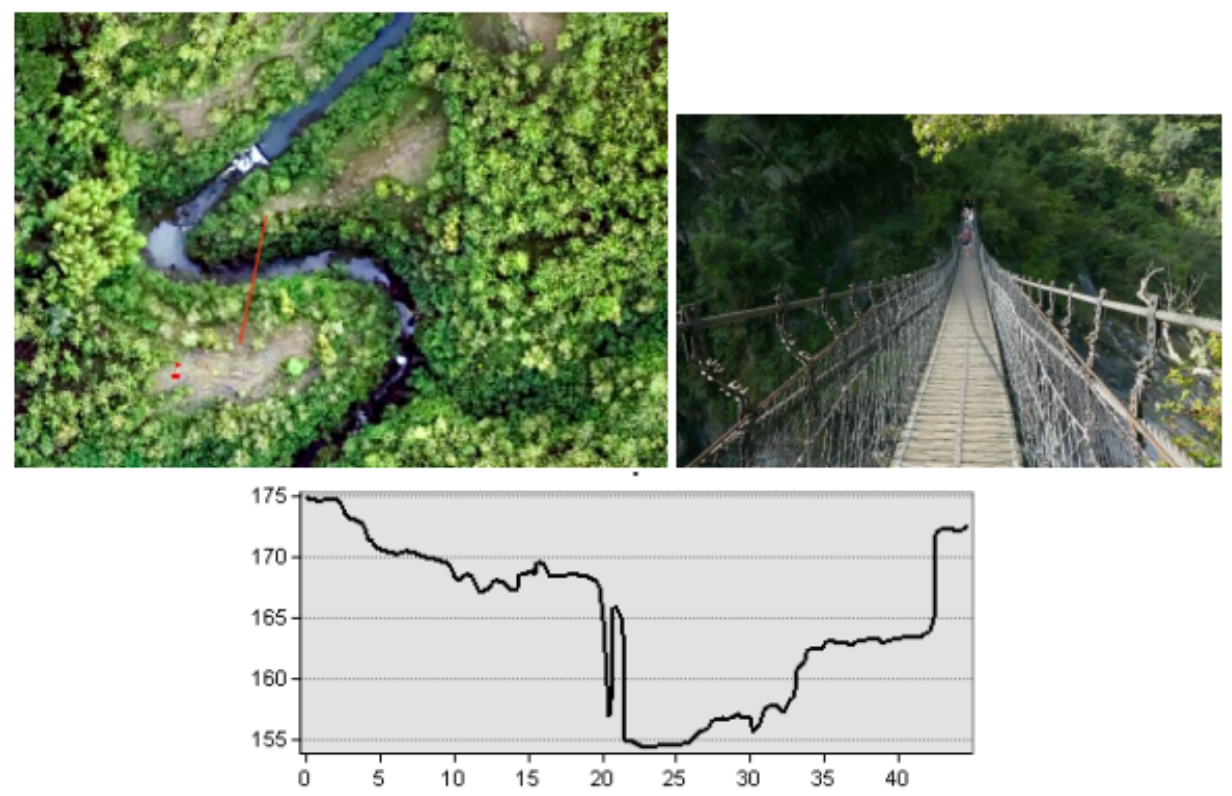

Figure 8. Bridge planning location with relatively same height (173-175 meter above mean sea level) and $46 \mathrm{~m}$ length of

\section{CONCLUSION}

Orthophoto and DSM can be used as a primary data analysis, such as knowing the conditions of land use and surrounding fields, measuring height differences, and terrain modeling such as viewshed to find out the visibility of an area from a certain point and suitability for attraction across the river. This research still needs to be developed for the overall planning in Kalisuci tourism area or other similar landforms.

\section{ACKNOWLEDGEMENT}

We would like to express my sincere gratitude to Community Development Directorate of Universitas Gadjah Mada, who has provided research funding support. Our sincere thanks also go to Pak Windarto as manager of Kalisuci Tourism Area and Amin Rahmadi, Kabut, also all crew of Kalisuci Tourism Area for the kind cooperation. We want to extend our sincere thanks to Lukman Ramadhani, S.Si. and Dony Octa S., S.Si as PT. Mitra Geotama Indonesia's team for technical data acquisition; also Mahmud Nur Safii as research assistants.

\section{REFERENCES}

[1] Aber J.S., Marzolff I, Ries J.B., [Small-Format Aerial Photography: Principles, Techniques and Geoscience Application], Elsevier, The Netherlands (2010). 
[2] Ahirwar, S., Swarnkar, R., Bhukya, S., Namwade, G., "Application of Drone in Agriculture," International Journal of Current Microbiology and Applied Sciences. 8. 2500-2505. 10.20546/ijcmas.2019.801.264 (2019).

[3] Alexander, N., Jenkins, L. An Application of Aerial Drones in Zoning and Urban Land Use. Ryerson University, Canada (2015).

[4] Beni, L.H., Jones, J., Thompson, G., Johnson, C., Gebrehiwot, “A. Challenges and Opportunities for UAV-Based Digital Elevation Model Generation for Flood-Risk Management: A Case of Princeville, North Carolina," Sensors 18, 3843; doi:10.3390/s18113843 (2018)

[5] Food and Agriculture Organization of The United Nation, E-Agriculture in Action: Drones for Agriculture. Food and Agriculture Organization of the United Nations and International Telecommunication Union, Bangkok, 2018

[6] Geospatial Information Agency. [Geospatial Information Agency's Regulation number 15 year 2014 concerning the Basic Map Accuracy Technical Guidelines], BIG, Cibinong, Bogor, Indonesia (2014).

[7] Gindraux, S., Boesch, R., Farinotti, D., "Accuracy Assessment of Digital Surface Models from Unmanned Aerial Vehicles' Imagery on Glaciers,” Journal Remote Sens. 2017, 9, 186 (2017).

[8] Handayani, W., Ayuningtyas, E.A., Rosaji, F.S.C., Setiawan, B.A., Argadyanto, B., "Unmanned Aerial Vehicle (UAV) Data Acquisition for Archaeological Site Identification and Mapping," IOP Conf. Ser.: Earth Environ. Sci. 98012017 (2017).

[9] Rokhmana, C.A., Utomo, S., "The Low-Cost UAV-Based Remote Sensing System Capabilities forLarge Scale Cadaster Mapping,” IOP Conf. Ser.: Earth Environ. Sci. 47012005 (2016).

[10] Rosaji, F.S.C, Nurteisa, Y.T., Hidayat, A.H., Handayani, W., "Aerial Photo Planning, Acquisition and Processing Using UAV Technology As an Alternative for Spatial Data Fulfillment," PIT Mapin, Bogor (2015).

[11] Rosaji, S.C.R., Handayani. W., Nurteisa, Y.T., Suharyadi., R., Widartono, B.S., "Aerial/Terrestrial Videography: An Alternative Remote Sensing Technology for Spatial Data Survey and Acquisition," Prosiding Simposium Nasional Sains Geoinformasi III - 2013, ISBN 978-979-98521-4-4 (2013).

[12] Safi'i, A.N., Aditya, A. "GPS Measurement Accuracy using RTK-NTRIP Method using INA-CORS BIG”. Prosiding Seminar Nasional Geomatika (2017).

[13] Santise, M., Fornari, M., Forlani, G., Roncella, R., "Evaluation of DEM Generation Accuracy from UAS Imagery," The International Archives of the Photogrammetry, Remote Sensing and Spatial Information Sciences, Volume XL-5 (2014).

[14] Turner, D., Lucieer, A. and Wallace, L., "Direct Georeferencing of Ultrahigh-resolution UAV Imagery,” IEEE Trans. Geosci. Remote Sens., 52(5), 2738-2745 (2014).

[15] Yeh, F.H., Huang, C.J., Han, J.Y., Ge, L., "Modeling Slope Topography Using Unmanned Aerial Vehicle Image Technique,” MATEC Web of Conferences. 147. 07002. 10.1051/matecconf/201814707002 (2018). 